\title{
EFEITOS DE UM TRABALHO COM A INTERTEXTUALIDADE NA FORMAÇÃO DE PROFESSORES DO ENSINO FUNDAMENTAL I
}

\author{
EFECTOS DE UN TRABAJO CON LA INTERTEXTUALIDAD EN LA \\ FORMACIÓN DE PROFESORES DE LA ESCUELA PRIMÁRIA
}

\section{EFFECTS OF A WORK WITH INTERTEXTUALITY IN TEACHERS EDUCATION ON ELEMENTARY SCHOOL}

\author{
Bethania Medeiros GEREMIAS ${ }^{1}$ \\ Priscila Stephanie Nigre CAVALCANTI ${ }^{2}$
}

RESUMO: A pesquisa invoca o conceito de intertextualidade como modo de construção de novos conhecimentos pelos estudantes. A partir de um diálogo teóricometodológico com os autores Damiani, Freire e Orlandi, nós desenvolvemos a dinâmica para Sucos e Teias para trabalhar leitura e escrita nas atividades de ensino da disciplina de Didática, do Curso de Pedagogia. Para obter acesso aos seus efeitos na aprendizagem dos estudantes utilizamos como material de análise a avaliação da disciplina escrita por eles. A análise, realizada por meio de um processo de des-superficialização do corpus investigado, possibilitou maior compreensão sobre os efeitos da intertextualidade na rotina acadêmica dos estudantes. A construção das Teias superou o cumprimento do conteúdo da disciplina de didática, na medida em que: i) favoreceu as leituras e releituras dos textos propostos no plano de curso: ii) possibilitou o entendimento e aprofundamento dos conceitos: iii) contribuiu para o estreitamento das relações entre os próprios estudantes e; iv) norteou a relação professor-aluno, oportunizando que os estudantes expusessem suas experiências, sentimentos e memórias.

PALAVRAS-CHAVE: Leitura. Escrita. Compreensão. Intertextualidade. Formação de professores.

RESUMEN: La investigación invoca el concepto de intertextualidad como modo de construcción de nuevos conocimientos por los estudiantes. A partir de un diálogo teórico-metodológico con los autores Damiani, Freire y Orlandi, desarrollamos la dinámica para "Sucos e Teias" para trabajar lectura y escritura en las actividades de enseñanza de la disciplina de Didáctica, del Curso de Pedagogía. Para obtener acceso a sus efectos en el aprendizaje de los estudiantes utilizamos como material de análisis la evaluación de la disciplina escrita por ellos. El análisis, realizado por medio de un proceso de des-superficialización del corpus investigado, posibilitó mayor comprensión

${ }^{1}$ Universidade Federal de Viçosa - (UFV), Viçosa - MG - Brasil. Professora da Área de Didática e Metodologias de Ensino. Departamento de Educação. Integrante do Grupo de Pesquisa Grupo de estudos dos clássicos contemporâneos da educação/CNPq. ORCID: <http://orcid.org/0000-0002-1188-7706>. Email: bmgeremias@ufv.br

${ }^{2}$ Universidade Federal de Viçosa - (UFV), Viçosa - MG - Brasil. Bolsista de Iniciação Científica PIBIC/CNPq. Departamento de Educação. Integrante do Grupo de Pesquisa Grupo de estudos dos clássicos contemporâneos da educação/CNPq. ORCID: <http://orcid.org/0000-0001-5999-1951>. E-mail: bmgeremias@ufv.br 
sobre los efectos de la intertextualidad en la rutina académica de los estudiantes. La construcción de las Tejas superó el cumplimiento del contenido de la disciplina de didáctica, en la medida en que: i) favoreció las lecturas y relecturas de los textos propuestos en el plan de curso: ii) posibilitó el entendimiento y profundización de los conceptos: iii) contribuyó al estrechamiento de las relaciones entre los propios estudiantes $y ; i v)$ orientó la relación profesor-alumno, oportunizando que los estudiantes expusieran sus experiencias, sentimientos y memorias.

PALABRAS CLAVE: Lectura. Escritura. Comprensión. Intertextualidad. Formación de profesores.

ABSTRACT: This research invokes the concept of intertextuality as a model of constructing new knowledge by students. From a theoretical and methodological dialogue with authors such as Damiani, Freire and Orlandi, we developed a dynamic for "Sucos e Teias" to work with reading and writing in educational activities for Didactics subject at Pedagogy Major. In order to obtain access to its effects on students' learning process we used as a material analysis the evaluation of the subject wrote by them. The analysis, done by a process of de-surfacing of investigated corpus, allowed a better comprehension about intertextuality effects on the academic routine of students. The construction of Teias exceeded the fulfillment of content in Didatic subject, as far as: $i)$ it favored readings and re-readings of proposed texts presented on the syllabus: ii) it provided understanding and deepening of concepts: iii) it contributed to the narrowing of relationships among students and: iv) it guided the relationship professor-student, creating opportunity so that students could expose their experiences, feelings and memories.

KEYWORDS: Reading. Writing. Comprehension. Intertextuality. Teachers Education..

\section{Introdução}

As metodologias de ensino voltadas para a leitura e a escrita na formação de pedagogos são foco de inquietação deste artigo, fruto de análise das aulas ministradas pela primeira autora. Entende-se que o processo de apropriação do texto transcende ao da memorização dos conceitos das disciplinas, pois demanda a compreensão dos estudantes sobre os textos lidos. Epistemologicamente, essa compreensão envolve, em uma perspectiva discursiva (PÊCHEUX, 2011), a possibilidade de relacionar as leituras anteriores dos estudantes - em outras disciplinas ou fora da universidade - com os temas e conceitos abordados nos textos.

Essa acepção invoca o conceito de intertextualidade como modo de construção de novos conhecimentos pelos estudantes. A leitura intertextual consiste em conceber o ato de ler e, o de escrever, como um processo de produção de sentidos, no qual as histórias de leitura dos sujeitos são ou precisam ser mobilizadas (ORLANDI, 2009; 
CHARAUDEAU; MAINGUENEAU, 2004). Por esse ângulo, as escolas e universidades se constituem como espaços de produção de autoria (GIRALDI, 2010), e a leitura é compreendida como interpretação, pois os sujeitos leitores intervêm com suas histórias e experiências diversas.

A partir de um olhar discursivo para o texto e seu contexto (ORLANDI, 2009; 2000), entendemos a compreensão leitora e a produção textual dos estudantes como um processo de construção permanente de redes de significações, compostas como um tecido. Isso implica dizer que as leituras de mundo, no sentido freireano (FREIRE, 2006, 1996, 1987), entram no jogo da construção da compreensão pelos estudantes dos textos trabalhados pelos professores nas suas aulas, sejam estes em sua forma escrita, oral ou imagética.

Paulo Freire (2006), em sua obra "A importância do ato de ler" invoca suas lembranças da leitura da primeira infância como elementos constitutivos da aprendizagem das primeiras letras e palavras, ou seja, como textos que, ao se entrelaçarem aos outros textos da sua primeira escola regular, contribuíram com o que o autor denominou de leitura da palavramundo. As palavras, assim como o texto, adquirem significado dinâmico e vivo, evocando a importância do conceito de intertextualidade, no qual a leitura mecânica, linear e solitária cede espaço para o diálogo com outros autores, outras leituras, outros textos e contextos.

Concordamos com o autor em sua crítica ao excessivo número de textos listados no rol das referências bibliográficas das disciplinas de graduação, pois focalizam na quantidade de material a ser memorizado, engolidos como pastilhas (SNYDERS, 1988), em detrimento de uma apropriação mais compreensiva, crítica e reflexiva pelos estudantes em formação inicial. Para Freire, a proposição de atividades de leitura compreensiva e, intertextual, implica a construção de uma rotina intelectual, na qual a rigorosidade do processo de formação docente requeira a exigência e a produção de uma leitura e escrita aprofundada dos textos lidos.

Essa preocupação é coerente com estudos e pesquisas em torno da temática abordada, socializados em eventos específicos, tal como o Seminário sobre leitura e produção no Ensino Superior (SLEPES), que teve sua décima versão realizada em 2015. Apesar de estar integrado à Associação Nacional de Pesquisa na Graduação em Letras (ANPOLL), é aberto aos profissionais de todas as áreas que investiguem as questões de leitura, escrita e produção do conhecimento. O foco na produção do conhecimento indica a relevância de investirmos em dinâmicas que aprofundem a relação dos 
estudantes com os objetos de estudo das diferentes disciplinas que compõem a grade curricular dos cursos de graduação.

Na sua décima versão, o tema geral intitulou-se "Os desafios da produção de conhecimento na universidade contemporânea". Para tanto foram elaboradas as seguintes provocações aos professores e estudantes pesquisadores: i) Quais teorias e reflexões nós estamos produzindo em diferentes áreas? ii) Quais pesquisas e conhecimentos estamos produzindo com vistas à formação de professores? iii) Como aliamos teoria e práticas? iv) Quais desafios e dificuldades permeiam a produção de conhecimento na universidade? (ANPOLL, 2015).

Com essas perspectivas de leitura e escrita no ensino superior e o papel dessas atividades na ampliação da compreensão dos textos desenvolvidos na disciplina de Didática, ministrada pela primeira autora, elaboramos um projeto de Iniciação Científica para investigar os efeitos de um trabalho intertextual na aprendizagem dos conceitos da didática pelos estudantes do curso de pedagogia.

Para tanto, realizamos uma dinâmica de leitura e escrita denominada Sucos e Teias, e desenvolvida por Damiani (2008). Esta consistiu na solicitação aos estudantes de, ao lerem alguns dos textos constantes no Plano de Curso, escrevessem uma síntese: suco, e as relações com outras leituras: teias (autores, filmes, imagens, memórias, experiências, etc.) para debate posterior em sala de aula.

Para obter acesso aos efeitos dessa dinâmica na aprendizagem dos estudantes utilizamos como material de análise a avaliação da disciplina feita por eles ao final do primeiro semestre de 2017. Pretendemos com esse trabalho socializar as análises produzidas pelas autoras e contribuir para os estudos que se propõem a investigar as possibilidades da intertextualidade no Ensino Superior.

\section{Sucos e teias: definição, abordagem e relações teóricas}

A partir de uma perspectiva epistemológica que considera que o trabalho com a leitura e escrita precisa ser pautado no diálogo com o texto e seu contexto buscou-se experiências voltadas para essa compreensão. Nesse processo, foi encontrado um artigo que socializava e analisava uma dinâmica que tinha como foco a intertextualidade.

Essa dinâmica foi denominada por sua autora de Sucos e Teias (DAMIANI, 2008). Sua finalidade era a de buscar modos de ler e compreender os textos no ensino 
superior, que considerassem a realidade acadêmica e a dificuldade dos estudantes em estabelecer relações com os textos lidos: áreas do conhecimento e suas vivências.

Para Damiani (2008), é fundamental que os docentes reflitam sobre suas rotinas acadêmicas, examinando regularmente suas práticas de utilização de textos. Dessa forma, ela faz uma junção entre a elaboração dos textos propostos e as relações destes com outras disciplinas, vivências, experiências e informações que os estudantes acumularam ao longo da sua trajetória de vida e escolar. A autora define: i) Suco como o relato sucinto do que o estudante compreendeu do texto, como um suco de fruta reduzido, porém concentrado; e, ii) Teias, como as conexões construídas entre o texto lido com as outras leituras realizadas ao longo da vida: vivências, experiências, conhecimentos, ideias e lembranças.

No debate em torno das elaborações dos estudantes, a autora considera importante a livre expressão, o estímulo e a valorização dos textos - teias - construídos pelos estudantes em um processo de leitura intertextual. As atividades intertextuais constituem-se como perspectivas condizentes com o modo como lemos os textos e contextos do cotidiano, seja ele escolar ou informal, envolvendo diferentes espaços de letramento: rua, casa, internet, escola/universidade, local de trabalho, etc.

Esse sentido amplo de texto converge com aquele defendido por Orlandi (2009): como uma unidade da qual o sujeito - analista ou leitor - busca atribuir sentidos. Segundo esta autora todo objeto simbólico é passível de ser lido, pode ser uma letra ou símbolo, um discurso oral, escrito ou imagético. Todo texto reclama sentidos e estes são produzidos de acordo com as histórias dos sujeitos e os diferentes contextos em que os objetos simbólicos circulam. Para se tornar discurso é preciso um trabalho com a historicidade, concebida como "o acontecimento do texto como discurso, o trabalho dos sentidos nele" (ORLANDI, 2009, p. 68).

A ideia de texto como unidade de análise, ou seja, como objeto do qual se parte para compreendê-lo, converge com a de Damiani (2008), de que a leitura feita pelos estudantes em formação necessita de uma participação ativa do sujeito com o texto, pois não basta fazer uma leitura superficial, é preciso ler e reler cuidadosamente, analisar e pensar sobre ele. O exercício do pensar a respeito do que se leu faz com que as memórias de leitura do sujeito-leitor sejam ativadas, agregando àquela leitura outros textos, ou seja, realizando um trabalho com a intertextualidade e, de certo modo, com a intersubjetividade, uma vez que os textos são produzidos por sujeitos, carregando as 
marcas de sua autoria e de tantos outros aos quais ele dialoga para produzir um novo texto (ORLANDI, 2009).

Paulo Freire (1987) contribui com esse diálogo entre os autores aqui abordados, pois compreende a palavra como ação, ou seja, “como significação atingida pela práxis, palavra cuja discursividade flui da historicidade - palavra viva e dinâmica, não categoria inerte [...]. Palavra que diz e transforma o mundo" (p. 20).

Percebe-se que ao concluir a graduação os estudantes se deparam com uma realidade distante daquelas vividas até então. Muitas vezes, a dificuldade de compreensão dos conceitos estudados durante a formação os amedronta e os oprime, por não terem acesso a outras práticas de leitura, além daquela repetitiva e mnemônica (TOURINHO, 2011). Pode-se remeter essa prática a uma concepção pedagógica que valoriza a paráfrase (repetição) em detrimento da polissemia, que implica a possibilidade de produção de novos sentidos e de ampliação do conhecimento pelos estudantes, pois para que haja compreensão pelos sujeitos dos textos lidos, nos ensina Orlandi (2009, p. 70):

[...] o leitor deve se relacionar com diferentes processos de significação que acontecem em um texto [...] compreender como um texto funciona, como ele produz sentidos, é compreendê-lo enquanto objeto linguístico-histórico, e explicar como ele realiza a discursividade que o constitui.

A probabilidade das dificuldades de leitura e produção textual persistirem após a formação inicial é consideravelmente grande, se pensarmos em um curso para futuros professores, no qual a escrita, a leitura e a compreensão de textos, principalmente os acadêmicos, são usadas como base em quase todas as disciplinas da grade curricular. Então, concorda-se com Freire (1993, p. 37) de que a leitura amparada na compreensão ampla dos textos "é um esforço que deve começar na pré-escola, intensificar-se no período da alfabetização e continuar sem jamais parar".

O modelo tradicional pedagógico de leitura e escrita centrado na memorização é criticado por Freire (1993), e destacado por Damiani (2008, p. 4): “é ultrapassado e seus resultados não são satisfatórios", pois rotula o estudante como um aprendiz passivo que nada faz para se apropriar do conhecimento, não considera o esforço do aluno e nem a realidade a qual está inserido. A autora defende que o aprendiz é um sujeito ativo, pois interage com o objeto que gera aprendizagem durante todo o processo do ler e escrever. 
Portanto, há que se incentivar e valorizar práticas de leitura e escrita que prezem o compartilhamento de ideias, opiniões e valores. Com esta finalidade, são descritos e analisados, posteriormente, resultados de pesquisa sobre os efeitos da dinâmica citada nas aulas da disciplina Didática I (EDU 150) de um curso de Pedagogia.

\section{Caminhos da pesquisa: ressignificando práticas e experiências}

A dinâmica Sucos e Teias, precedentemente abordada, foi adaptada e desenvolvida pela primeira autora do artigo, professora da disciplina de Didática I (EDU 150) e orientadora do Projeto de Pesquisa: Efeitos de um trabalho com a intertextualidade no curso de Pedagogia: o caso da dinâmica sucos e teias, financiado pelo Programa Institucional de Bolsas de Iniciação Científica (PIBIC) do Conselho Nacional de Desenvolvimento Científico e Tecnológico (CNPq).

O financiamento do projeto compreende o período de 01 de agosto de 2017 a 31 de julho de 2018. Ele está sendo desenvolvido em duas etapas:

i) primeiramente estamos analisando as avaliações dos estudantes sobre a atividade de leitura e escrita nos moldes do Sucos e Teias, para investigar alguns dos efeitos de sua efetivação no processo de construção do conhecimento envolvendo o conteúdo programático da disciplina. Este é o objeto de análise e discussão do presente artigo.

ii) posteriormente, iremos analisar as tipologias de textos que são relacionados pelos estudantes no processo de escrita, ou seja, compreender quais teias serão construídas, quais os textos que são materializados pelas memórias de leitura dos estudantes e aqueles que se materializam com mais frequência, como exemplos: fala de um professor; texto de outra disciplina; citação de um autor; experiência vivida na escola/universidade; uma imagem; um vídeo, etc.

Essa dinâmica foi adaptada ao ser utilizada nas aulas de Didática pela professora da disciplina. Na versão de Damiani (2008), os estudantes deveriam elaborar os sucos e as teias em todos os textos. Porém, para esta disciplina foram escolhidos três textos, considerando que o produto dessa leitura também foi utilizado como atividade avaliativa, em perspectiva formativa e focada na construção do conhecimento (HOFFMANN, 2011).

No plano de curso, foi proposta a construção dos Sucos e teias dos textos de: Albuquerque (2002) - Retrospectiva histórica da Didática e do Educador; Oliveira e 
Freitas - Currículo e Avaliação de Oliveira e Fernandes (2007) e o de Freire - Quinta a Sétima Carta (1997).

Uma breve descrição do conteúdo desses textos é relevante para a compreensão do modo como os estudantes se manifestaram em relação aos textos lidos para a realização dos seus Sucos e Teias e dos efeitos em suas aprendizagens sobre os mesmos. O trabalho de Albuquerque (2002) conta a trajetória da didática e como ela foi influenciada pelos acontecimentos históricos brasileiros, até as perspectivas atuais. Oliveira e Fernandes (2007) abordam inquietações sobre as práticas educativas de ensinar e aprender, refletindo sobre currículo e as avaliações escolares. Freire (1993) dialoga sobre o ensinar a aprender, as relações entre educador e educando, a rotina dos professores dentro da escola, a prática pedagógica e a importância do professor se engajar para ouvir os alunos, buscar entendê-los e respeitá-los.

Ao final da disciplina a primeira autora solicitou aos estudantes que realizassem uma análise sobre as metodologias utilizadas por ela ao longo da disciplina, dentre estas a dinâmica em questão. A partir desse momento começamos nosso trabalho de leitura. Primeiramente, identificamos os estudantes por meio de uma denominação alfanumérica de E1 a E55, pois cinquenta e cinco (55) estudantes estavam matriculados na disciplina EDU 150 e responderam as questões da avaliação. A forma de denominação escolhida está em conformidade com a exigência de preservação das identidades dos sujeitos da pesquisa formuladas pelo Comitê de Ética em Pesquisas com Seres Humanos (CEP).

No processo de análise é primordial considerar a questão que move o trabalho dos analistas/pesquisadores (ORLANDI, 2009). Partindo da questão: Quais os efeitos de um trabalho com a intertextualidade no Ensino Superior?, utilizamos as avaliações dos estudantes sobre a dinâmica Sucos e Teias como corpus da pesquisa. Um olhar compreensivo, embasado epistemologicamente na Análise de Discurso (AD) para esse corpus é de um objeto discursivo e, como tal, ele necessita de um trabalho de interpretação e de compreensão.

Com base nesse olhar discursivo, nós lemos diversas vezes os textos (avaliação dos estudantes) e os organizamos em um quadro em função dos efeitos que foram se materializando durante as leituras. A finalidade foi de realizar um trabalho de desuperficialização (ORLANDI, 2009), que consiste num primeiro tratamento do material bruto coletado. Esse tratamento, que já é analítico, "demanda um ir-e-vir constante, entre teoria, consulta ao corpus e análise" (p. 67). Com esta orientação, buscamos 
compreender os efeitos da metodologia empregada no processo de ensino-aprendizagem dos conteúdos e conceitos abordados na disciplina ministrada.

\section{Discussão: os efeitos da intertextualidade no processo de ensino-aprendizagem}

Durante as diversas leituras do corpus, ou seja, do trabalho de passagem do texto ao discurso e, por meio da leitura de cada resposta e de redução dos textos semelhantes (parafrásticos), fomos construindo alguns temas aglutinadores. Com esta forma de análise dos textos das respostas dos estudantes obtivemos quatro temas principais, que correspondem aos efeitos da dinâmica no processo de ensino-aprendizagem da disciplina: i) conteúdos da didática; ii) compreensão do conhecimento; iii) exercício da criticidade; iv) relação professor-aluno/aluno-aluno.

Após esse primeiro tratamento, iniciamos a análise triangular, considerando as nossas interpretações, a avaliação (textos) dos estudantes e o debate no campo teórico. Apresentamos abaixo os temas obtidos por meio do processo de des-superficialização do corpus investigado. No decorrer da análise, apresentamos alguns excertos dos textos/avaliações dos estudantes para maior compreensão dos mesmos.

\section{- Conteúdos da didática}

As relações construídas pelos estudantes envolvendo os conteúdos da didática são analisadas a partir dos objetivos e finalidades propostos no plano de curso da disciplina EDU 150. Quinze estudantes relataram que a dinâmica proporcionou conhecer um novo fazer docente, pois os textos trabalhados por meio dos Sucos e Teias lhes permitiram compreender a prática docente de forma diferenciada, além de facilitar a apropriação dos conhecimentos:

a dinâmica facilitou o aprendizado e a apropriação dos textos pelos alunos. Os sucos e teias, além de inovador, é totalmente aplicável em qualquer outra disciplina, pois me fez pensar a respeito as minhas vivências e fazer conexões sem fim, entre os textos trabalhados, minhas experiências escolares e pessoais (E13).

a dinâmica foi interessante e útil, pude ter novas concepções e desconstruir conceitos (E17).

Seis estudantes disseram que é preciso aprender para construir o conhecimento. Exemplificamos com a análise feita por E26: 
os sucos e teias me proporcionou o aprendizado que deve ser difundido e apropriado, e que a didática de um professor é de extrema importância para o processo de ensino-aprendizagem.. o docente não deve ser um mero disseminador de teorias, é necessário que essas teorias virem objeto apropriação, formando saberes e resultando em uma prática de excelência.

Outros seis estudantes escreveram que não existe uma didática, mas sim várias maneiras de ensinar: saberes diferentes. Para Freire (1993, p.27), há uma relação entre o aprender e o ensinar, que vemos materializada na fala dos estudantes. Para o autor, há uma relação direta e de troca entre o ensinante e o aprendiz, pois um contribui com o aprendizado do outro. Essa compreensão tem relação com o modo como os estudantes relacionam o texto lido com outras leituras e experiências. Para eles a dinâmica proporcionou um conhecimento maior dos textos trabalhados, na medida em que considerou as diferentes formas do saber.

Além dessa relação com a experiência, os estudantes relatam uma transformação no modo como percebiam o ensino e a avaliação, o que remete aos conteúdos presentes nos textos trabalhados em sala de aula. Segundo os estudantes, a melhor compreensão dos temas é um efeito da dinâmica investigada.

\section{- Compreensão do conhecimento}

Uma melhor compreensão dos conhecimentos se sobressai nos dizeres dos estudantes. Os efeitos de sentido construídos por eles fazem menção à ideia de conhecimento como uma construção. Relacionamos esse sentido ao envolvimento ativo do aprendiz no seu processo de aprendizagem, concordando com Freire (2006) de que as nossas experiências de vida, a realidade na qual estamos inseridos, é que contribui ou permite a construção e a compreensão de determinado conhecimento:

[...] não podemos duvidar que a nossa prática nos ensina [...] conhecemos muitas coisas por causa da nossa prática. Desde muito pequenos aprendemos a entender o mundo que nos rodeia. Por isso, antes mesmo de aprender a ler e escrever palavras e frases, já estamos lendo, bem ou mal, o mundo que nos cerca. Mas este conhecimento que ganhamos de nossa prática não basta. Precisamos ir além dele. Precisamos conhecer melhor as coisas que já conhecemos e conhecer outras que ainda não conhecemos (p. 70-71). 
Nos textos dos trinta e um estudantes a compreensão do que se lê implica a problematização e a socialização dos saberes, obtidos por meio das experiências e do resgate de memórias:

No decorrer do curso de didática, obtive a compreensão da importância de se problematizar algo tão corriqueiro e essencial para a socialização de saberes, como é a didática e, através dos sucos e teias eu pude conhecer um novo fazer docente, por ser pautado na cooperação, ao trabalhar em grupos, mas, sobretudo, na contextualização dos conteúdos (E1).

Para nove estudantes a dinâmica proporcionou melhor relação entre alunosalunos e alunos-professores, possibilitando a troca de saberes e vivências. O texto de E9 nos auxilia a compreender esse efeito:

a interação entre os grupos foi ótima, pois nos proporcionou uma troca de conhecimento e notícias muito importantes. A relação alunoaluno foi muito produtiva, pois a partir da dinâmica pudemos interagir e aprender muito uns com os outros, sempre levando em consideração o ponto de vista de cada um.

Vemos em Freire (2006) a importância da prática na construção do conhecimento, pois em sua perspectiva começamos nossas primeiras leituras a partir do mundo que nos rodeia, ou seja, a prática também nos ensina. Contudo, o autor destaca a importância de ultrapassar o domínio da prática. É preciso “conhecer melhor as coisas que já conhecemos e conhecer outras que ainda não conhecemos" (p. 71). Por isso, compreendemos que a aprendizagem dos conteúdos da disciplina está associada nos textos dos estudantes com a compreensão do conhecimento como uma construção intersubjetiva - entre sujeitos e experiências - o que envolve não somente a teoria estudada nos cursos de formação de professores, mas a prática.

Essa inseparabilidade entre conteúdo e prática, conceito e experiência, implica o que o autor denomina práxis. Conforme o autor, a compreensão será tão mais profunda quanto sejamos capazes de associar, jamais dicotomizar, os conceitos emergentes da experiência escolar aos que resultam da cotidianidade. Um exercício crítico sempre exigido pela leitura e necessariamente pela escrita é o de como nos darmos facilmente à passagem da experiência sensorial que caracteriza a cotidianidade à generalização que se opera na linguagem escolar e desta ao concreto tangível (1993, p. 29-30). 
Essa relação entre construção do conhecimento e criticidade se materializa na avaliação dos estudantes como elementos constitutivos do processo do aprender os conteúdos da disciplina.

\section{- Exercício da criticidade}

Ao analisarmos os efeitos da dinâmica debatidos anteriormente, percebemos uma inter-relação entre eles, nos permitindo interpretar que o exercício da criticidade é um efeito aglutinador dos outros dois analisados: os conteúdos da didática e a compreensão do conhecimento.

Nas avaliações dos estudantes sobre a formação de um pensamento crítico são evocados: o estímulo ao desejo de aprender, o trabalho com a memória e a construção de novos conhecimentos.

Para chegarmos a essa categoria foram analisados relatos que puderam compor as subcategorias acima citadas. Trinta e três (33) estudantes reconheceram que os Sucos e Teias é uma metodologia importante para o aprendizado, pois nos leva a relacionar os textos e discussões com outras disciplinas e vivências de cada aluno, conforme relato do E5 em destaque:

\footnotetext{
A professora superou as expectativas trazendo a bagagem cultural dos discentes, respeitando e valorizando suas histórias com a temática dos sucos e teias, onde foi possível relacionar as experiências tanto no âmbito educacional escolar como no pessoal, $e$ cada aluno pode se expressar sem represálias ou medo de ser criticado pelo professor e colegas da turma.
}

Observamos o exercício da interdisciplinaridade nessa dinâmica, pois ela não se esgota em sua forma, ela faz com que o estudante pense para além do conteúdo estudado, fazendo relações com o exterior.

Nove (09) estudantes enfatizaram que a dinâmica trouxe a possibilidade do exercício da criticidade, da objetividade, do resgate de memórias, de uma leitura de mundo mais profunda e formação de opinião, como podemos destacar no texto abaixo:

As metodologias utilizadas foram se tornando muito interessantes no decorrer do tempo. Sucos e teias trouxe a possibilidade do exercício da criticidade, da objetividade, do resgate de memórias, de uma leitura do mundo mais profunda (E1).

Dez estudantes relataram que a dinâmica contribuiu para melhor assimilação do conteúdo. Podemos exemplificar com a avaliação de E30: 
A metodologia Sucos e teias nos ajuda e estimula muito a ler os textos, nos faz pensar no que estamos lendo e também a articular com experiências pessoais, com o que já lemos no decorrer da vida, com outras disciplinas etc.

Sua avaliação sobre a dinâmica vai ao encontro do que defende Freire (1993, p.29) sobre a leitura dos textos:

[...] estudar é, em primeiro lugar, um que-fazer crítico, criador, recriado, não importa que eu nele me engaje através da leitura de um texto que trata ou discute um certo conteúdo que me foi proposto pela escola ou se realizo partindo de uma reflexão crítica sobre um certo acontecimento social ou natural e que, como necessidade da própria reflexão, me conduz à leitura de textos que minha curiosidade e minha experiência intelectual me sugerem ou que me são sugeridos por outros.

Para ele não há uma separação entre o ato de ler, a aprendizagem e a produção de sentido. Todos devem acontecer do modo integrado, pois enquanto o sujeito lê, ele traz leituras do mundo que o rodeia. Suas experiências e memórias ajudam a conduzir a leitura produzindo múltiplos sentidos, que podem fugir ao controle do sujeito (ORLANDI, 2009). Por essa razão, o papel da mediação nos cursos de formação de professores é fundamental, pois é na relação professor-aluno/aluno mediados pelo conhecimento que se dá a passagem da leitura primeira para a compreensão mais elaborada dos textos lidos.

- Relação professor-aluno/aluno-aluno

A Relação professor-aluno faz referência à construção do conhecimento, mas de forma mediada. Dez estudantes citaram que a dinâmica permitiu conhecer cada colega, constituindo um mosaico de identidades através da construção dos Sucos e Teias:

A metodologia sucos e teias favoreceu o entrosamento da turma melhorou a relação aluno-professor e aluno-aluno (E48).

A dinâmica foi feita em cooperação com os demais companheiros de percurso, me permitiram perceber cada colega como um mosaico de identidades, no qual um professor ou um aluno é uma posição, uma identidade no interior deste mosaico, ou seja, isto se constitui um exercício de alteridade (E1).

Essa leitura dos estudantes sobre o trabalho realizado retoma nossa discussão anterior sobre o papel da intersubjetividade, ou seja, da construção coletiva dos 
conhecimentos propostos na disciplina, acompanhada de um diálogo de saberes/experiências dos sujeitos.

Nesta categoria quinze estudantes consideraram a dinâmica gostosa, instrutiva, estimulante e interessante. Vejamos alguns excertos de suas avaliações:

\begin{abstract}
O sucos e teias foi uma atividade gostosa e instrutiva, entender o contexto em que fui inserida na escola relembrando de professores, é fundamental para formação e para evitar ao máximo que os erros se repitam com nossos futuros alunos. Além de ser um material riquíssimo que utilizo em outras aulas. Ressalto que a didática utilizada foi de fácil compreensão, conseguiu prender minha atenção, não tornou o conteúdo maçante e enjoativo, buscando sempre inovar nas aulas (E18).
\end{abstract}

Os sucos e teias é uma metodologia excelente e inovadora, que faz com que os alunos possam interligar seus conhecimentos (E38).

Conforme esses estudantes, de um modo geral, houve a compreensão de que o conteúdo não foi maçante e enjoativo, foi justa a forma de avaliação e houve interação entre professor e aluno. Conforme destacado pelo E22:

com a dinâmica a forma de avaliação foi justa não baseada em decorebas, mas com métodos que fato nos levaram à reflexão acerca de nosso futuro como educadores.

De certo modo, esses efeitos relativos aos aspectos mais subjetivos e emocionais foram repetidamente citados na avaliação. Por meio desses relatos, podemos analisar que a dinâmica Sucos e Teias tornou a leitura dos textos atrativa, possibilitando aos mesmos analisarem não somente a quantidade de conteúdo, mas a qualidade da proposta da disciplina. Além disso, foi evocada pelos estudantes a importância da comunicação entre professor e aluno e da preparação profissional para a prática docente. Segundo Freire (1993, p. 67) um

[...] aspecto que fundamental ligado à primeiras experiências docentes das jovens e a que as escolas de formação, se não dão, deviam dar imensa atenção é o da formação das professorandas para "leitura" da classe de alunos como se esta fosse um texto a ser decifrado, a ser compreendido.

Nesse sentido, as cartas de Paulo Freire (1993), escritas na obra Professora Sim, tia não, lidas durante a disciplina, são material de reflexão sobre a profissão docente e seu papel no contexto da sala de aula, possibilitando uma compreensão do próprio processo formativo dos estudantes. 


\section{Considerações finais}

A análise preliminar dos efeitos da dinâmica, realizada por meio de um processo de des-superficialização do corpus investigado, possibilitou maior compreensão sobre os efeitos da intertextualidade na rotina acadêmica dos estudantes, e estendeu-se às suas relações exteriores.

Em síntese, a construção das Teias superou o cumprimento do conteúdo da disciplina de didática, na medida em que: i) favoreceu as leituras e releituras dos textos propostos no plano de curso; ii) possibilitou o entendimento e aprofundamento dos conceitos; iii) contribuiu para o estreitamento das relações entre os próprios estudantes e; iv) norteou a relação professor-aluno, abrindo oportunidade para que os estudantes expusessem suas experiências, sentimentos e memórias.

Estas categorias, construídas por nós no processo de análise, corroboram em parte àquelas de Damiani (2008), tais como: compreensão em maior grau de profundidade e internalização mais eficiente; estabelecimento de interconexões com outros conteúdos anteriormente trabalhados e com experiências vivenciadas, bem como a reflexão sobre novos conteúdos.

Contudo, acreditamos que novos modos de aplicação da dinâmica, com uma seleção menor de textos, em conjunto com as especificidades da disciplina de Didática, possibilitaram outras compreensões sobre o trabalho realizado, dentre estas destacamos as múltiplas produções de sentido materializadas durante as discussões das teias pelos estudantes e no processo de análise das mesmas; a importância de se estabelecer uma quantidade menor de textos a serem trabalhados com esta dinâmica, pois acreditamos que isto leva a maior aprofundamento dos conteúdos e comprometimento com a construção do Sucos e Teias.

Além disso, percebemos um distanciamento do trabalho de Damiani no que diz respeito ao envolvimento e avaliação dos estudantes sobre a dinâmica, pois ela destaca que somente a metade da turma realizou as avaliações, e dessas, muitas expressaram como ponto negativo a grande quantidade de textos e a frequência da elaboração do mesmo. Em nosso trabalho, verificamos que todos os estudantes da turma participaram da dinâmica e da avaliação final, na qual expressaram suas opiniões sobre a utilização, efeitos e construção dos Sucos e Teias. A liberdade de construção de relações infinitas, de acordo com os estudantes, permitiu outras leituras, memórias, experiências, histórias, 
imagens, fotos, filmes, etc. Estas também puderam ser expressas em diferentes formatos, como: textos, mapas conceituais, esquemas, tópicos, dentre outros.

Assim como um texto é lido diferentemente em tempos diferentes, em contextos e pessoas diferentes, as metodologias de ensino, quando aplicadas em disciplinas e com outros estudantes, estão sujeitas a transformações, aportando novos modos e olhares sobre a construção de conhecimentos pelos estudantes em formação.

Nesse jogo de produção de sentidos sobre os textos lidos, convocamos três conceitos importantes para se pensar a construção dos conhecimentos do Ensino Superior: a intertextualidade, a intersubjetividade e a interdisciplinaridade. Esses conceitos remetem ao sentido de conhecimento como objeto mediado, envolvendo as relações dos estudantes com eles mesmos, com os professores, as demais disciplinas e seus professores, os textos e seus autores, as memórias de leituras e a produção de sentidos situacionais.

Compreende-se que a dinâmica de Sucos e Teias, acrescida ao diálogo teórico com as perspectivas discursiva e freireana, permitiu uma rica relação com outros textos (escritos, orais, imagéticos), mas também com as leituras de mundo (FREIRE, 2009) dos estudantes em formação.

Concluímos que as compreensões de leitura, trazidas por esses autores, se revelam, quando colocadas em funcionamento nas salas de aula universitárias, uma novidade para os estudantes, pois eles podem de maneira simples e dinâmica evidenciar ou exteriorizar suas experiências menosprezadas ao longo da sua trajetória escolar ou acadêmica.

\section{REFERÊNCIAS}

ALBUQUERQUE, M. J. de. Retrospectiva histórica da Didática e do Educador. Educação: teorias e práticas, Ano 2, n. 2, dez., 2002.

\section{ASSOCIAÇÃO NACIONAL DE PESQUISA NA GRADUAÇÃO EM LETRAS. X Seminário de Leitura e Produção no Ensino Superior, 2015.}

CASSIANI, S.; GIRALDI, P.M; LINSINGEN, I. von. É possível propor a formação de leitores nas disciplinas de Ciências Naturais? Contribuições da análise de discurso para a educação em ciências. Educação: Teoria e Prática, v. 22, n. 40, maio/ago., 2012.

CHARAUDEAU, P.; MAINGUENEAU, D. Dicionário de Análise do Discurso, São Paulo, Contexto, 2004. 
DAMIANI, M. F. Trabalhando com textos no ensino superior. Revista Portuguesa de Educação, v. 21, n. 2, 2008, p. 139-159.

FELICÍSSIMO, M. Análise do discurso e leitura: o sujeito, o texto e o sentido.

Memento: Revista do Mestrado em Letras Linguagem, Discurso e Cultura, n. 2, v. 1, jul./ago., 2009.

FREIRE, P. A importância do ato de ler: em três artigos que se complementam, São Paulo: Cortez, 2006.

FREIRE, P. Pedagogia da autonomia: saberes necessários à prática educativa. São Paulo: Paz e Terra, 1996.

FREIRE, P. Professora Sim, Tia Não: cartas a quem ousa ensinar. São Paulo: Olho d'água, 1993.

FREIRE, P. Pedagogia do oprimido, Rio de Janeiro: Paz e Terra, 1987.

GIRALDI, P. M. Leitura e escrita no ensino de ciências: espaços para produção de autoria. 2010, 350f. Tese (Doutorado em Educação Científica e Tecnológica) Programa de Pós-Graduação em Educação Científica e Tecnológica, Universidade Federal de Santa Catarina, Florianópolis, 2010.

HOFFMANN J. M. L. Avaliação: mito e desafio - uma perspectiva construtivista. 41 ${ }^{\mathrm{a}}$ ed. Porto Alegre: Mediação, 2011.

OLIVEIRA; C. de O.; FREITAS, L. C. Indagações sobre currículo: currículo e avaliação. Brasília: Ministério da Educação, Secretaria de Educação Básica, 2007.

ORLANDI, E. P. Discurso em análise: sujeito, sentido, ideologia. Campinas, SP: Pontes Editores, 2012.

ORLANDI, E. P. Análise de discurso: princípios e procedimentos. $8^{\mathrm{a}}$. ed. Campinas, SP: Editora Pontes, 2009.

ORLANDI, E. P. Discurso e leitura. 5. ed. São Paulo: Cortez; Campinas: Editora da Unicamp, 2000.

PÊCHEUX, M. Sobre o contexto epistemológico da Análise de Discurso. In:

ORLANDI, E. P. (Org.). Análise de discurso: Michel Pêcheux. Textos selecionados. $2^{\mathrm{a}}$ Ed. Campinas, SP: Pontes Editores, 2011.

SNYDERS, G. Alegria na Escola, São Paulo: Manole Ltda, 1988.

TOURINHO, C. Refletindo sobre a dificuldade de leitura em alunos do ensino superior: "deficiência" ou simples falta de hábito? Revista Lugares de Educação, v. 1, n. 2, p. 325-346, jul./dez., 2011 
AGRADECIMENTOS: Agradecemos ao Conselho Nacional de Desenvolvimento Científico e Tecnológico $(\mathrm{CNPq})$ pelo financiamento da pesquisa por meio de bolsa de Iniciação Científica.

\section{Como referenciar este artigo}

GEREMIAS, Bethania Medeiros.; CAVALCANTI, Priscila Stephanie Nigre. Efeitos de um trabalho com a intertextualidade na formação de professores da educação básica. Revista Ibero-Americana de Estudos em Educação, Araraquara, v. 13, n. 4, p. 15801597, out./dez., 2018. E-ISSN: 1982-5587. 10.21723/riaee.unesp.v13.n4.out/dez.2018.11197

Submetido em: 15/03/2018

Revisões requeridas: $19 / 03 / 2018$

Aprovado em: 08/05/2018 